\title{
EXPENDITURE PATTERN AMONG INDONESIAN MANUFACTURING WORKERS: CASE STUDY IN PULAU PINANG
}

\author{
Siti ‘Aisyah Baharudin \\ Universiti Sains Malaysia \\ sab15@usm.my
}

\begin{abstract}
This study is conducted to provide an understanding of the pattern of expenditure among Indonesian female manufacturing worker's remittances in Malaysia. A total of 100 Indonesian women workers were randomly selected. The location of the study is two manufacturing companies in Penang. Structured interview questions are used to analyze descriptive data. In this study, most of the respondents earn monthly income of RM1000RM1999 with $44 \%$ and monthly living cost is between RM1-RM499. There are four main variables that determine the respondents' expenditure pattern; remittance, debt, entertainment, and food expenditure. The result found that $84 \%$ of respondents always send money to Indonesia every month. Furthermore, $42 \%$ of respondents have debt. There are $81 \%$ of respondents who always spend their money for entertainment purposes and $53 \%$ of respondents choose to buy a ready food.
\end{abstract}

Keywords: Demographic Economics, Wages, Labor Mobility, Immigrant Workers, Labor Policy

JEL Classification: J1, J3, J6

\section{INTRODUCTION}

The theoretical insight to understand the income distribution of migrant workers can be drawn from permanent income hypothesis developed by Milton Friedman. The notion of permanent income hypothesis is that consumption depends on what people expect to earn over considerable period of time. Permanent Income hypothesis theory also describes the behavior of consumers who wish to obtain maximum satisfaction with the consumption of goods within his/her budget. Subsequently, Friedman states that individual's consumption patterns are influenced primarily on changes in lifetime's income instead of current income (Meghir, 2004).

Moreover, the cost of living index theory introduced by (Konüs, 1939) gives an understanding toward the expenditure pattern on the daily living cost of migrant workers. The theory of cost of living index applies directly to the measurement of consumption price such as price index for the personal consumption expenditure which is the component of gross domestic product. The cost of living index theory emphasizes that individual can attain the same standard of living in any ways as such individual can substitutes goods that have similar purpose. The theory also suggested that substitutes imply that differing collection of goods may still represent equivalent standard of living (Triplett, 1992).

According to Malaysian Government's provision, migrant workers are classified into two categories; they are namely low skilled workers and professional workers. Professional workers are those who earn salary of RM 3000 above per month. On the other hand, low skilled workers are workers earn salary below RM 2500. Migrant workers expansion in Malaysia is break down into three waves. The first wave occurred from 1975-1985, the 
second wave occurred from 1986 to 1998 , and lastly the third wave started from 1998 onwards (Kanapathy, 2006). Since then, started from 1990, the inflows of migrant workers in Malaysia have steadily increased after government introduced formal guidelines on migrant workers enforcement. However, the presence of undocumented or illegal workers resulted to inaccurate estimation on number of migrant workers.

In 1991, the number of migrant workers in Malaysia accounted for $4.4 \%$ over the Malaysian population and rose to $5.9 \%$ in 2000 (Kassim, 2005). In 1995, Malaysia had become the largest labor importer countries in Asia. However, due to Asian financial crises 1997, the number declined significantly and then picked up again as the economic condition has been stabilized. In addition, most of the migrant workers were employed in manufacturing, agriculture, domestic worker, as well as construction (Piper, 2005). Furthermore, in the beginning of 2000s, the number of legal migrant workers in Malaysia accounted for 1.4 million and more than 50 percent dominated by Indonesian. While at the same year there was 1.2 million undocumented migrant workers arrived in Malaysia. In most cases, it happened in a state of Sabah and Sarawak where the country's border is thought less strict (Navamukundan, 2007).

Figure 1
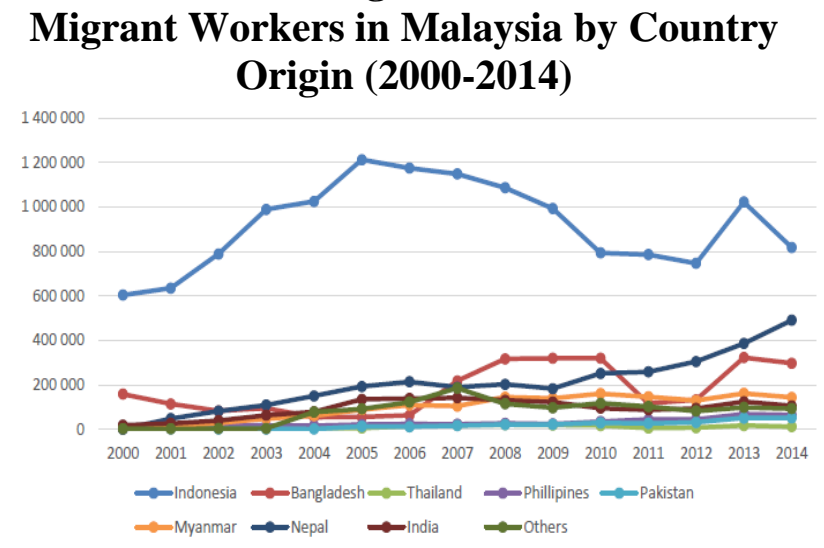

Source: Ramli (2017)
According to figure 1, the number of Indonesian workers in Malaysia had increased over time from 600,000 thousand workers in 2000 and the number was doubled in 2005, while at the same time reached its peak number. Since then, the number of Indonesian workers continuously declined until 2012, with roughly only 690,000 workers been employed. In 2010, from the total number of Indonesian migrant workers, Saudi Arabia absorbs $40 \%$ of the total workers, as compared to Malaysia who employed only $23 \%$ (Djafar \& Hassan, 2012). In addition, the figure clearly depicts in the last 15 years, Indonesian migrant workers were dominating the proportion of migrant workers in Malaysia compared with workers from other countries.

Among the factors Malaysia is chosen as a destination country for employment is such as the opportunity difference and the level of employment growth, the difference between the expected salary and the same language factors (Sukimi \& Sarifin, 2014). Indonesian migrant workers dominate the total population of migrant workers in Malaysia by $60 \%$, while at the majority of Indonesian workers in Malaysia are female workers (Hernandez-Coss et al., 2008). This view has been supported by (Subadi et al., 2013) who claimed about $72 \%$ of Indonesian migrant workers in Malaysia in 2005 were female workers. More specifically they were employed as domestic workers. In 2012, the level of unemployment in Indonesia was hit $6.32 \%$ of the total population or 7.6 million people not having a job. This occurred because there is imbalance between the supply and demand in the domestic labor market (Mafruhah et al., 2012).

The massive outflow of Indonesian female manufacturing workers to various countries is intended by the government as an effort to reduce unemployment (Rahman, 2011). In fact, many other positives also derived from this policy by helping the government strengthen the economy in a way that it makes more favorable exchange rate 


\section{SITI 'AISYAH BAHARUDIN}

\section{Expenditure Pattern Among Indonesian Manufacturing Workers: Case Study In Pulau Pinang}

from the remittance sent back home as well as to increase the welfare of the family left in home country and therefore overall economy indicators are boosted. (Meier, 2014) divided the expenditure pattern of migrant workers into two different stage, namely short term and long term effect. The short term effect tend to put priority on primary needs as the expenditure on food shares increasing, while the consumption on non-food items are neglected at this stage. Otherwise, more money spends on medical services and utilities at the long term stage while food consumption decreases.

The study issue is to look at the expenditure pattern on migrant workers with respect to their monthly income. Commonly, the reason for migrant workers to work abroad is to find job with higher income as compared to the income in the origin country. In addition, the cost of living in the host country might be different with the origin country. Thus some questions arise as to whether their income is sufficient to fulfill the needs in the host country? What are the items they typically spend on? And is remittance is the highest monthly expenditure they spend from their income? The objective of this paper is to analyze the expenditure pattern of Indonesian female manufacturing workers in Penang.

\section{LITERATURE REVIEW}

The empirical studies on the economic condition of migrant workers associated with their income, saving, and expenditure have been extensively examined by many researchers who raised the issues from different countries. A study completed by (Saikia, 2014) found that there is a significant change in income after workers migrate to the new place. Increase of the income also determined by the skill level possessed by each worker. The more advanced the skill of the worker is associated with higher level of income. Unfortunately, this higher income is not accompanied with awareness to save and make investment from their income as it found that the saving and investment behavior is very poor. In addition, the expenditure pattern on foods is found to be identical among the workers, yet the other expenditures are varies. Furthermore, (Rahman et al., 2014) supported the above study and found that Bangladeshi migrant workers in Malaysia spend most of their income on remittance which used by family in the home country for daily living cost as well as children's school tuition fee. As the result, they only left small portion to save. Likewise, (Orbeta Jr \& Zosa, 2009) supported the idea that people are willing to work in oversea because they can earn higher income and can channeled it to remittance which used to pay off debt, fulfill daily living cost, and children's education.

Kumcu (1989) investigated the difference on saving behavior of migrant workers from Turkey who come from urban and rural area. Other than that, educational level as well as occupational category does not influence much on the saving behavior of the workers. Nonetheless, age does have significant effect on the saving behavior. According to the research produced on Indonesian female manufacturing workers in plantation sector in Kedah, Malaysia by (Mafruhah et al., 2012) result examined the distribution of worker's monthly income where living cost, remittance, and saving are ranked from highest to lowest portion. Income also used to pay monthly bills and entertainment purpose. Another distinctive finding revealed from the study as there is a difference in the treatment of remittance by the workers from previous studies mentioned above, in this study the authors found that remittance is used for their personal saving in form of gold and bank as well as personal investment in home country.

Sripana (2012) analyzed that Vietnamese migrant workers in Malaysia are able to save but only in small amount and spend most of the income to pay back the debt of predeparture cost. Study also found that gender 
has an important effect on the level of saving, Female workers tend to be more cautious to spend the money thus they can save more. In contrast, male workers are more vulnerable to spend the money on the leisure purposes such as gambling, drink, and clothes. This result in line with (Bormann et al., 2010) who found that migrant workers in two sample electronic companies in Penang, Malaysia are working to pay high amount of debt caused by illegal recruitment fees at the home country imposed by recruiting agent.

Moreover, evidence from China which studied the consumption and social integration of migrant workers suggested that there is positive relationship between the levels of income towards the social integration. Besides that, most of the workers spend the income for entertainment purposes in order to attain certain level of social integration (Huang \& Liu, 2016). Further finding from Ngin et al. (2010) observed that workers from four different sectors have a distinctive pattern on expenditure. They classified expenditure into two main categories, specifically necessary and non-necessary goods. The study found that food expenses, electricity bills, and housing rentals are necessary goods that have highest priority. Conversely, fishing, phone credit, cigarettes, as well as alcohol beverages are among non-necessary goods consumed by workers across the four sectors. Identical finding from (Saikia, 2016) revealed that the expenditure of food items as a dominant expenses for migrant workers in Kerala, India. On the other hand, the non-food items come later. In addition, they only remit amount of money left after food items are fulfilled.

\section{METHODOLOGY}

The data set used in this study is a primary data that collected from questionnaire which was carried out from January 2018 until February 2018. The target respondents in this study are Indonesian female manufacturing workers in Pulau Pinang. The rationale behind the selection of female workers is due to the fact that the portion of female manufacturing workers in Malaysia captures 70 to $80 \%$ from the total foreign manufacturing workers in Malaysia (Hamidi, 2016). Where the population is unknown, the sample size can be derived by computing the minimum sample size required for accuracy in estimating proportions. A total of 100 Indonesian female manufacturing workers in Pulau Pinang from two factories namely Panasonic Automotive Systems Malaysia Sdn. Bhd. and Renesas Semiconductor (M) Sdn. Bhd. are participated in the survey.

The rationale behind the choice of the location study is because Penang known as one of the biggest free industrial zones in Malaysia, whereby plenty of multinational companies from different parts of the world are operated. Furthermore, the study is conducted in most concentrated area where Indonesian female manufacturing workers are lived. Two areas are chosen, namely Bayan Lepas and Bukit Mertajam. A self-administered questionnaire is distributed randomly to respondents. In addition, respondent is asked to fill up a set of questionnaire form which consists related to issue of the study. Data will be analyzed with descriptive and quantitative analysis method with the help of SPSS software. The results of the study will also be translated into tables and charts to simplify the analysis.

\section{RESULTS AND DISCUSSION}

This study involved the income and the cost of living migrant worker. The study was conducted on 100 Indonesian female manufacturing workers in two factories in Pulau Pinang. Quantitative analysis provides a percentage for each variable used. Whereas, descriptive analysis describes the reason that influence the percentage of the variable.

\section{Respondent Profile}

First and foremost, the respondent profile analysis begins with the analysis of age. There 


\section{SITI 'AISYAH BAHARUDIN \\ Expenditure Pattern Among Indonesian Manufacturing Workers: Case Study In Pulau Pinang}

are five age categories designed in the questionnaire, which are 15-19 years old, 2024 years old, 25-29 years old, 30-34 years old and 35-39 years old. From the analysis, out of these five categories, the age 15-24 years old contribute to the highest portion with $48 \%$. Moreover, the age 20-24 followed by 25-29 and 30-34 years old is ranked as the second to the fourth with the percentage of $26 \%, 23 \%$, and $3 \%$ respectively. Yet, none of the respondent is in the age between 35-39 years old because the required age as per described by Indonesia Embassy for migrant workers in Malaysia except for housemaid (18-38 years old). As for the marital status of the respondents, $70 \%$ respondents are single and another $30 \%$ is married.

Education background in the questionnaire is divided into five categories namely no formal education, primary school, middle school, high school as well as university. Overall, $69 \%$ of the respondent's latest education was high school, it followed by middle school which constitutes to $16 \%$ from the total respondents. Primary school and university both share the same percentage of 7 $\%$. Last but not least, only $1 \%$ of the respondent has no formal education background. Overall, the analysis shows the latest education of female manufacturing workers in Penang is high school. This is due to the regulation from Indonesian government that requires high school as a minimum education attainment for migrant workers candidate. Subsequently, the years since migration of the respondents in the analysis reveals that majority of them are already working in Malaysia for 2-3 years. There are 47 respondents or $47 \%$ under this category. Then, $26 \%$ respondents are working for 4-5 years. Followed by 0-1 years, 6-7 years, and $>7$ years with the contribution of $17 \%, 8 \%$, and $2 \%$ respectively. This data shows that the respondents in this study are relatively new workers.
In this study, most of the respondents earn monthly income of RM1000-RM1999 with $44 \%$. Moreover, RM2000-RM2999 ranked as the second highest income earned by the respondents, just slightly different from the majority, which is $28 \%$. Followed by $14 \%$ of the respondents earn the monthly income of RM1-RM999. Additionally, income of RM3000-RM3999 contributes $10 \%$ out of total data collected. Last but not least, only 4 $\%$ of the respondents have an income more than RM4000.

\section{Expenditure pattern}

From the total 100 respondents in the survey, $42 \%$ of them reveal that their monthly living cost is between RM1-RM499. After all, $28 \%$ respondents say that their monthly living cost is lying between RM500-RM999. Similarly, another $28 \%$ respondents spend RM1000-RM1499 per month for living cost. Additionally, a very small portion of the respondents with $2 \%$ spend RM1500-RM1999 monthly. Lastly, none of the respondents spend money above RM2000 per month. There are 4 main types of expenditure including remittance, debt, entertainment and food.

\section{a. Remittance expenditure}

This section provides more comprehensive analysis on the remittance expenditure pattern of the respondents involved in this study. The analysis shows that from 100 respondents, $84 \%$ of them always engaged in remittance transaction every month. Otherwise, the remaining $16 \%$ says do not always send money to Indonesia every month due to couple of reasons. Among one of the reasons is that they work in Malaysia for noneconomic motive which do not obligate them to regularly send money to Indonesia. Furthermore, the frequencies of remittance from those $84 \%$ respondents who regularly send money to Indonesia, mostly they send 1-2 times per month. This captures $88 \%$ from the total $86 \%$ respondents who regularly send 
money every month. It followed with small portion of the respondents who send money 34 times per month $(11 \%)$ as well as 5-6 times per month (1 \%). Moreover, $91 \%$ of the respondents claim to send money through formal channel which includes bank and other legal remittance companies. The remaining 9 $\%$ sends money through informal channel such as individual agent or other unauthorized remittance channels. The amount of money being sent is mostly in between RM1-RM999 (56\%). In the second place, respondents send money from RM1000-RM1999 (38 \%). Lastly, it found just few people send RM2000RM2999 (6 \%).

\section{b. Debt expenditure}

As for debt expenditure, this section tells deeper analysis on the respondent's expenditure over the debt. Initially, the analysis first comes with the portion of respondents with or without the ownership of debt. From the data that has been collected and analyzed, it found that $58 \%$ of the respondents have no debt, while the other $42 \%$ respondents have debt. Out of $42 \%$ respondents who own a debt, it is identified that $89 \%$ of them have debt with non-bank party. In addition, $9 \%$ have a debt with bank and another $2 \%$ with other parties that are not classified in the questionnaire. Furthermore, the questionnaire was asked the respondents about the type of item that is bought or borrowed with debt. There are two items classified namely cash and personal belonging. The result from the analysis shows that majority of the respondents have a debt on cash money rather than personal belonging. The percentage is significantly higher on cash with $64 \%$, while only $36 \%$ for personal belonging. Typically, they own a debt from RM100-RM199 (41 \%) in the first place. It followed with $25 \%$ respondents have a debt from RM300-RM399. The others have debt of RM0-RM99, RM200-299, and >RM400 with percentage of $18 \%, 9 \%$, and $7 \%$ respectively.

\section{c. Entertainment expenditure}

As for entertainment expenditure, $81 \%$ of respondents spend their monthly income for entertainment purpose. On the other hand, the remaining $19 \%$ do not have expenditure on entertainment. Half of the total $81 \%$ respondents voted to spend their entertainment expenditure for shopping. Furthermore, in the second place, respondents are willing to spend on vacation as their entertainment expenditure (35\%). Last but not least, expenditure on cinema is voted by $15 \%$ of the respondents. By looking at the expenditure amount on entertainment purpose, majority of respondents (38) are willing to spend RM100-RM199 per month for entertainment. There are also $22 \%$ respondents spend RM200-RM299 per month. Followed by RM300-RM399 which chosen by $20 \%$ respondents. Another $19 \%$ respondent spends RM0-RM99; while the least amount is choose by $1 \%$ respondent for amount greater than RM400.

\section{d. Food expenditure}

Food expenditure pattern starts with the question on the behavior of the respondents to get the food. Two choices are being made, whether they get the food by cooking or buy ready food. Respondents reveal that $53 \%$ of them prefer to buy a ready food instead of cooking. Moreover, $72 \%$ of out of those $53 \%$ respondents reveal that they do not have time to cook by themselves, so that they buy ready food. Besides that, another $17 \%$ say they cannot cook, $6 \%$ say it is cheaper if they buy ready food, another $4 \%$ answer this because they do not have a facility to cook at the hostel, and the remaining $1 \%$ for other reasons. However, there are also another $47 \%$ respondents who prefer to cook. Majority of them like to cook because it is cheaper than buy ready food $(45 \%)$. It followed by the opinion that $34 \%$ of them used to cook. Apart from that, for another $15 \%$ respondents, they prefer to cook because they can adjust their own taste. Last but not least, the availability of 


\section{SITI 'AISYAH BAHARUDIN}

\section{Expenditure Pattern Among Indonesian Manufacturing Workers: Case Study In Pulau Pinang}

cooking facilities is voted by only $6 \%$ of the respondents. Typical respondents from this study spend RM200-RM299 for their monthly food expenses. The percentage shows $33 \%$ of them spend that amount. However, with just slightly difference, $32 \%$ respondents spend RM100-RM199. Moreover, it followed with $18 \%$ and $16 \%$ respondents who pay RM300RM399 and RM0-RM99 per month. Only $1 \%$ of respondent spends more than RM400 per month for food.

\section{CONCLUSION}

This study is conducted to analyze the expenditure pattern among Indonesian manufacturing workers in Penang. Four types of expenditure namely remittance, debt, entertainment, and food expenditure are analyzed. All in all, the field survey conducted in this study tells that $84 \%$ of the respondents in this study regularly perform remittance transaction every month with the most frequent amount is 1-2 times per month. On the other hand, the least amount transaction is 5-6 times per month as suggested by the respondents. Moreover, the amount of money being sent is majority in the range of RM0-RM999. Additionally, the remittance transactions are heavily done through formal channels. The fact that most of the respondents regularly perform remittance transaction can be linked up with the finding from motive to migrate which shows the tendency to migrate due to economic motive instead of non-economic motive. Therefore, one of the directions of their income is channeled to support the family in home country through remittance. Furthermore, only $42 \%$ of the respondents in the study found to have a debt. It mostly found that the debt is used to borrow money either from bank or non-bank party. However, the result shows non-bank party is significantly higher than bank party. Thus, it creates assumption that their salary might not be adequate to accommodate their needs although the sum of debt is still acceptable. After all, respondents in the study reveal their willingness to spend their income for entertainment purpose. As the data shown, more than three fourth of the total respondents frequently spend on entertainment purpose, mainly for personal shopping. The amount being spent is varied from RM100-RM400. The behavior on the food expenditure is differentiated with their preference to buy or to cook the food. Those who prefer to buy food explained the time constraint as the main reason for them not to serve the food by themselves. Otherwise, economic value is the reason to those who prefer more on cooking their own food.

\section{REFERENCES}

Bormann, S., Krishnan, P. \& Neuner, M. E. (2010). Migration in a Digital Age: Migrant Workers in the Malaysian Electronics Industry; Case Studies on Jabil Circuit and Flextronics. World Economy, Ecology and Development.

Djafar,, F. \& Hassan, M. K. H. (2012). Dynamics of push and pull factors of migrant workers in developing countries: The case of Indonesian workers in Malaysia. Journal of Economics and Behavioral Studies, 4(703).

Hamidi, M. (2016). Indonesian female factory workers: the gendered Migration policy in malaysia. PEOPLE: International Journal of Social Sciences, 2.

Hernadez-Coss, R., Brown, G., Buchori, C., Endo, I., Todoroki, E., Naovalitha, T., Noor, W. \& Mar, C. (2008). The Malaysia-Indonesia remittance corridor: Making formal transfers the best option for women and undocumented migrants. World Bank Publications.

Huang, X. \& Liu, X. (2016). Consumption and social integration: Empirical evidence for Chinese migrant workers. Economics Discussion Papers.

Kanapathy, V. (2006). Migrant workers in Malaysia: An overview. Country paper 


\section{JURNAL OPTIMUM, Volume 10, Nomor 1 Maret 2020}

prepared for Workshop on East Asian Cooperation Framework for Migrant Labour, Kuala Lumpur.

Kassim, A. (2005). Cross-border movement of foreign workers in Malaysia: A comparative analysis. 78-91

Konüs, A. A. (1939). The problem of the true index of the cost of living. Econometrica: Journal of the Econometric Society, 10-29.

Kumcu, M. E. (1989). The savings behavior of migrant workers: Turkish workers in W. Germany. Journal of Development Economics, 30(273-286).

Mafruhah, I., Sarsito, T. \& Gravitiani, E. (2012). The Welfare of the Indonesian Migrant Workers (TKI) in the Land of a Malay Nation: A Socio-Economic Analysis. Southeast Asian Journal of Social and Political Issues, 1 (246-271).

Meghir, C. (2004). A retrospective on Friedman's theory of permanent income. The Economic Journal, 114(293-306).

Meier, K. (2014). Low-Sskilled labor migration in Tajikistan: Determinants and effects on expenditure patterns.

Navamukundan, A. (2007). Labour migration in Malaysia-Trade union views. Trends in the Regions.

Ngin, N. L., Chulasai, L. \& Charoenloet, V. (2010). The right to decent work of Myanmar migrant labors working in Thailand: A case study of Phang-nga. Journal of Economics Chiang Mai University, 14(92-111).

Orbeta Jr, A. \& Zosa, V. (2009). The social and economic impact of Philippine international labor migration and remittances. PIDS Discussion Paper Series.

Piper, N. (2005). Migrant Labor in Southeast Asia. Country study: Singapore. Ms, prepared for the Friedrich Ebert Stiftung project on Migrant Labor in Southeast Asia. Singapore: Asia Research Institute.

Ramli A. R. (2017). Divulging foreign workers issues in Malaysia. In. Siti Hamisah Tapsir, Alice Suriati Mazlan, Zuraidah A. M., Ramlee A. R., Suhana S., \& Nik Zainun N. M. (Eds.) Foreign labour in Malaysia: Selected works (11-18). Malaysia, Ministry of Higher Education.

Rahman, M. (2011). Gender dimensions of remittances: a study of Indonesian domestic workers in East and Southeast Asia.

Rahman, M., Uddin, M. S. J. \& Albaity, M. (2014). Socio-economic conditions of bangladeshi migrant workers in Malaysia. Journal of Basic and Applied Scientific Research, 4(3)246-252.

Saikia, D. (2014). Economic Conditions of the in-migrant workers in Kerala: A Case Study in the Trivandrum District. Journal of Indian Research, 2(4)33-46.

Saikia, D. (2016). The socio-economic status of migrant workers in Thiruvananthapuram District of Kerala, India. Journal of Economic and Social Thought, 3(113).

Sripana, T. (2012). The Socio-Economic Plight of Vietnamese Labor in Malaysia. Understanding Confluences and Contestations.

Subadi, T., Ismail, R., Pos, S. J. A. Y. T. \& Indonesia, P. S. (2013). Indonesian female migrants and employers' mistreatment in Malaysia: A case of domestic servants from Central Java. PEOPLE: International Journal of Social Sciences, 3.

Triplett, J. E. (1992). Economic theory and BEA's alternative quantity and price indexes. Survey of current Business, 72(49-52). 